\title{
STATIC AND ROTORDYNAMIC ANALYSIS OF COMPOSITE BLADE MARINE PROPELLER
}

\author{
Arun V. Javir ${ }^{1 *}$, Omkar P. Bhatkar ${ }^{2}$, Ashutosh More ${ }^{3}$, Bhavin Lad ${ }^{4}$, Nikhil Todkari ${ }^{5}$, Tushar Karande ${ }^{6}$ \\ ${ }^{1,2}$ Assistant Professors and ${ }^{3,4,5,6}$ Students \\ *1,2,3,4,5,6 Mechanical engineering, Rajendra Mane College of Engineering and Technology, Ambav, Devrukh, Ratnagiri: \\ - 415612., Mumbai University \\ ${ }^{4}$ Email: bhavin.lad27@gmail.com,3ashutoshmore8892@gmail.com
}

\section{*Corresponding Author: -}

\begin{abstract}
-
This project work deals with modelling and analysing the propeller blade of a marine vehicle for their strength. A propeller is a complex geometry which requires high end modelling software. The solid model of propeller is developed by using Solid work 2014 \& Mat lab R12.The meshing is generated for the model using Ansys. Static and rotor dynamic analysis of composite blade propeller is carried out in ANSYS 14.5 software. The stresses obtained are well within the limit of anisotropic property of the materials. The deflection for composite blade propeller is determined. Optimal solution was found by using TAGUCHI method. The critical speed of the propeller is determined using rotor dynamic. On comparison which shows that by changing different parameters like speed of shaft and pressure of water on propeller we found optimum solution for the design of propeller.
\end{abstract}

Index Terms- Model, blade, hub, Analysis, Static, Rotor dynamic, Taguchi.

\section{(a) $(\$)$}




\section{INTRODUCTION}

The movement of a ship through water is achieved by the power so developed in the engine via the propeller shaft to the propeller in water. The distance or forward motion depends mainly on the propeller pitch which is defined as how far the propeller can travel for one revolution of the shaft.

The marine time industry, uses nickel-aluminumbronze (NAB) as the primary material for propeller construction. This is done for many reasons, including its anti-biofouling characteristics, high stiffness, and low corrosion potential. However, NAB is a cathodic metal. While it experiences little corrosion itself, its presence leads to galvanic corrosion of the surrounding hull steel. The detailed objectives of the research is to evaluate a hub design, perform a structural design of marine composite blade propeller.

\section{OBJECTIVE}

- To study the function and geometry of propeller.

- To determine feasibility of carbon fibre as propeller material through analysis.

- To determine a suitable design for composite blade marine propeller.

- To create CAD model and perform FEA analysis.

- To provide bolt arrangement to hub and blades of propeller for easy maintenance.

\section{DEFINITION OF TERMS RELATING TO PROPELLER DESIGN}

- Diameter - The diameter of the imaginary cycle scribed by the blade tips as the propeller rotates.

- Radius - The distance from the axis of rotation to the blade tip. The radius multiplied by two is equal to the diameter.

- Blade face - The pressure side, pitch side. Aft side of the blade surface facing the stern.

- Blade number - Equal to the number of blades on the propeller.

- Blade tip - Maximum reach of the blade from the centre of the hub separates the leading and trailing edges.

- Hub - Solid cylinder located at the centre of the propeller. Bored to accommodate the engine shaft. Hub shapes include cylindrical, conical, radius and barrelled.

- Blade root - Fillet area. The region of transition from the blade surfaces and edges to the hub periphery. The area where the blade attaches to the hub.

- Pitch $(\boldsymbol{P})$ - The linear distance that a propeller would move in one revolution with no slippage.

- Rake - The fore or aft slant of a blade with respect to a line perpendicular to the propeller axis of rotation.

- wake $(w)$ - This explains the overall disturbances created by the motion of the ship as a result of the drag of the hull, the streamline flow past the hull and the wave

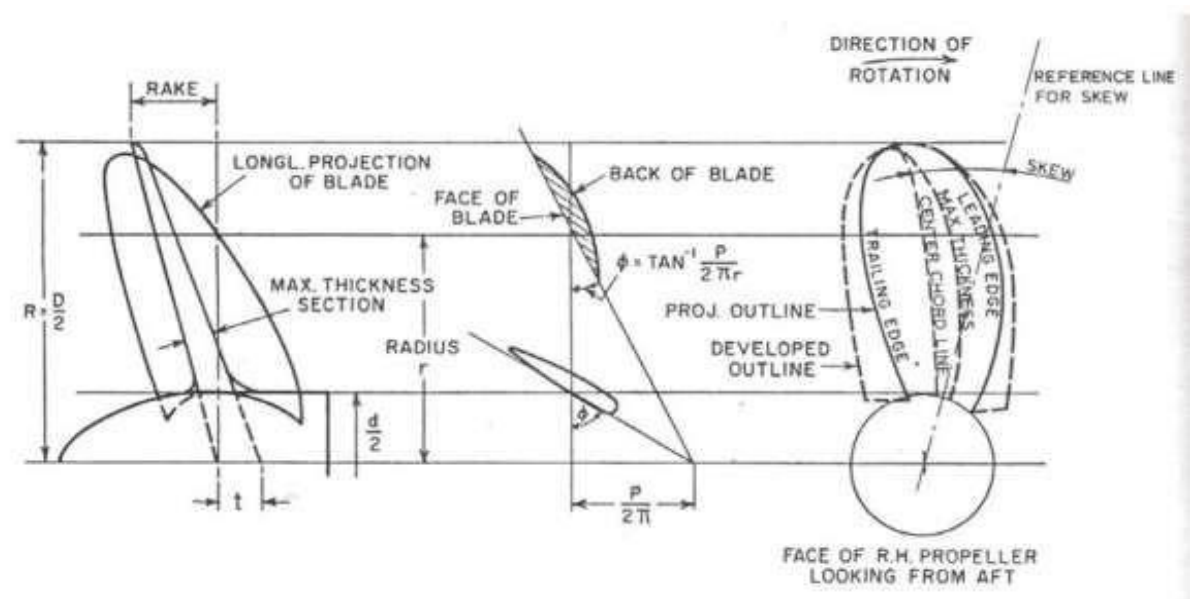

Fig. 1. Terms relating to propeller design [1]

patterns formed by the ship on the surface water.

- Developed Area $\left(\boldsymbol{A}_{\boldsymbol{D}}\right)$ - This is the actual area of driving faces.

- Projected Area $(\boldsymbol{A p})$ - This is the sum of the blade areas projected into a plane which is perpendicular to the axis of the screw

- Expanded Area $\left(A_{E}\right)$ - This is the sum of area of all blades enclosed in an expanded blade outline outside the hub. [ 1]

\subsection{Basic formulae}

Developed area ratio $=D A R=\frac{A_{D}}{A_{Q}}$ 


\section{Projected area of the blade \\ (on trasverse plane) outside hub $=A_{P}$}

Projected area ratio $=P A R=\frac{A_{P}}{A_{O}}$

Blade width ratio $=B W R$

$$
=\frac{\text { max. blades (outside hub) }}{D}
$$

Diameter $=D$ and Pitch $=P$

Pitch ratio $=\frac{P}{D}$

No. of blade $=4$ nd

pitch angle $=\phi$

Disk area $=$ area of tip circle $=\frac{\pi D^{2}}{4}=A_{o}$

Developed area of blades, outside hub $=A_{D}$

\section{CONCEPT}

In this project manganese bronze is use for hub material as it has very corrosion resistance property. Propeller blade made up of 'Epoxy carbon woven 230GPa wet' as it has high stiffness and strength. Propeller blade and hub assembled by Allen key head bolt arrangements. Hub fitted on shaft by means of keyway.

\section{MATERIAL}

Nickel-aluminium-bronze is the standard material for marine propellers. There are several reasons for this, including its corrosion characteristics and anti-biofouling qualities. A nickel aluminium bronze propeller's role in the corrosion of the ship is reasonably simple. Galvanic corrosion is cathodically controlled, meaning that the extent of corrosion experienced is directly proportional to the amount of "electron taking" material present; the anode (in most cases, the steel hull and sacrificial anodes) begins to rust away. The primary cathode in the marine environment surrounding the hull is the NAB propeller. It does not corrode itself; however, it will cause significant steel plating rust and wastage of the sacrificial anodes. Hence By using composite material instead of cathodic NAB material we can prevent ship from corrosion. Composite is combination of a resin with fibres. Its favourable stiffness and strength properties contributed to the selection of carbon as the propeller material. Since a propeller blade is very similar to a loaded cantilever beam, most of the fibers were oriented in the zero-degree configuration, which extends radially from the hub.

\subsection{Properties of Epoxy carbon woven 230GPa wet}

Table 1. Property of Epoxy carbon woven 230GPa wet.

\begin{tabular}{|c|c|}
\hline Density & $1251 \mathrm{~kg} \mathrm{~m}{ }^{\wedge} 3$ \\
\hline $\begin{array}{c}\text { Orthotropic Elasticity } \\
\text { Young's modulus X } \\
\text { direction }\end{array}$ & $5.916 \mathrm{E}+10 \mathrm{pa}$ \\
\hline $\begin{array}{c}\text { Young's modulus } \mathrm{Y} \\
\text { direction }\end{array}$ & $5.916 \mathrm{E}+10 \mathrm{pa}$ \\
\hline $\begin{array}{c}\text { Young's modulus } Z \\
\text { direction }\end{array}$ & $7.5 \mathrm{E}+09 \mathrm{pa}$ \\
\hline Poisson's ration XY & 0.04 \\
\hline Poisson's ration YZ & 0.3 \\
\hline Poisson's ration XZ & 0.3 \\
\hline Shear modulus XY & $1.7 \mathrm{E}+10 \mathrm{pa}$ \\
\hline Shear modulus YZ & $2.7 \mathrm{E}+09 \mathrm{pa}$ \\
\hline Shear modulus XZ & $2.7 \mathrm{E}+09 \mathrm{pa}$ \\
\hline $\begin{array}{c}\text { Orthotropic stress } \\
\text { limits }\end{array}$ & \\
\hline Tensile X direction & $5.13 \mathrm{E}+08 \mathrm{pa}$ \\
\hline Tensile Y direction & $5.13 \mathrm{E}+08 \mathrm{pa}$ \\
\hline Tensile Z direction & $5 \mathrm{E}+07 \mathrm{pa}$ \\
\hline $\begin{array}{c}\text { Compressive X } \\
\text { direction }\end{array}$ & $-4.37 \mathrm{E}+08 \mathrm{pa}$ \\
\hline Compressive y direction & $-4.37 \mathrm{E}+08 \mathrm{pa}$ \\
\hline $\begin{array}{c}\text { Compressive Z } \\
\text { direction }\end{array}$ & $-1.5 \mathrm{E}+08 \mathrm{pa}$ \\
\hline Shear XY & $1.2 \mathrm{E}+08 \mathrm{pa}$ \\
\hline Shear YZ & $5.5 \mathrm{E}+07 \mathrm{pa}$ \\
\hline Shear XZ & $5.5 \mathrm{E}+07 \mathrm{pa}$ \\
\hline Ply type & Woven \\
\hline Type & \\
\hline
\end{tabular}


5.2. Properties of manganese bronze

Table 2. Property of manganese bronze.

\begin{tabular}{|c|l|}
\hline Density & $7888.8 \mathrm{Kgm}^{\wedge}-3$ \\
\hline Isotropic Elasticity & \\
\hline Young's modulus & $1.16 \mathrm{E}+11 \mathrm{pa}$ \\
\hline Poisson's ration & 0.34 \\
\hline Bulk modulus & $1.2083 \mathrm{E}+11 \mathrm{pa}$ \\
\hline Shear modulus & $4.3284 \mathrm{E}+10 \mathrm{pa}$ \\
\hline Tensile Ultimate strength & $6.55 \mathrm{E}+08 \mathrm{pa}$ \\
\hline $\begin{array}{c}\text { Compressive Ultimate } \\
\text { strength }\end{array}$ & $3.45 \mathrm{E}+08 \mathrm{pa}$ \\
\hline
\end{tabular}

\section{DESIGN PARAMETER}

Twin Screw Passenger Ferry

Ship speed $(\mathrm{Vs})=15.5$ knots

Delivered power $=836 \mathrm{kw}$

$1137 \mathrm{hp}(\mathrm{m})$ Revolutions

$=300 \mathrm{rpm}$

Wake fraction $=0.112$

Speed of Advance = 13.764 knots

Diameter $=1.980 \mathrm{~m}$

Blade number $=4$

$W \max -W \min =0.3$

$W \max =0.35$

Tip clearance $=1.0 \mathrm{~m}$ Ship displacement $=1118 \mathrm{~m} \wedge 3 \mathrm{~d} / \mathrm{R}=1.110$

Boss radius $0.23 \mathrm{R}$

Table 3. Dimension of blade.

\begin{tabular}{|c|c|c|c|}
\hline $\mathbf{r} / \mathbf{R}$ & $\begin{array}{c}\text { Chord } \\
(\mathbf{m m})\end{array}$ & $\begin{array}{c}\text { Pitch } \\
(\mathbf{m m})\end{array}$ & $\begin{array}{c}\text { Thick } \\
(\mathbf{m m})\end{array}$ \\
\hline 1.0000 & 0 & 1765 & 4.0 \\
\hline 0.9375 & 410 & 1784 & 7.7 \\
\hline 0.8750 & 538 & 1795 & 12.0 \\
\hline 0.7500 & 668 & 1789 & 21.1 \\
\hline 0.6250 & 705 & 1772 & 31.2 \\
\hline 0.5000 & 688 & 1734 & 42.3 \\
\hline 0.3750 & 627 & 1671 & 55.4 \\
\hline 0.2500 & 518 & 1564 & 72.0 \\
\hline 0.1667 & 416 & 1432 & 85.7 \\
\hline
\end{tabular}

Basic propeller

Propeller Ae/A0 0.627

Kq 0.0192

P/D mean 0.869

Kt 0.123

H 00.675

J 0.678

Thrust 4.9

tonnes

\section{SOFTWARE BASED MODELING}

To model a propeller blade of particular series type aerofoil points of specific type are required. In present work a Bseries standard aerofoil points are chosen for the modelling. The outline aerofoil points of the propeller are generated by using MATLAB R12. These co-ordinate files are use and propeller blade are modelled in Solid works 2013 and the hub and filleting portion of blade are done in the same software. Since the propeller blade consisting of various radii are located through corresponding pitch angles. Then all rotated sections are projected onto a right circular cylinder of respective radii as shown in fig below. Then by using multi section surface option, the blade is modelled.

\subsection{Phase one}

7.2. Phase two

Fig (2), Use of MATLAB R12 for generation of co- As per the concept of project, necessary ordinate file. 


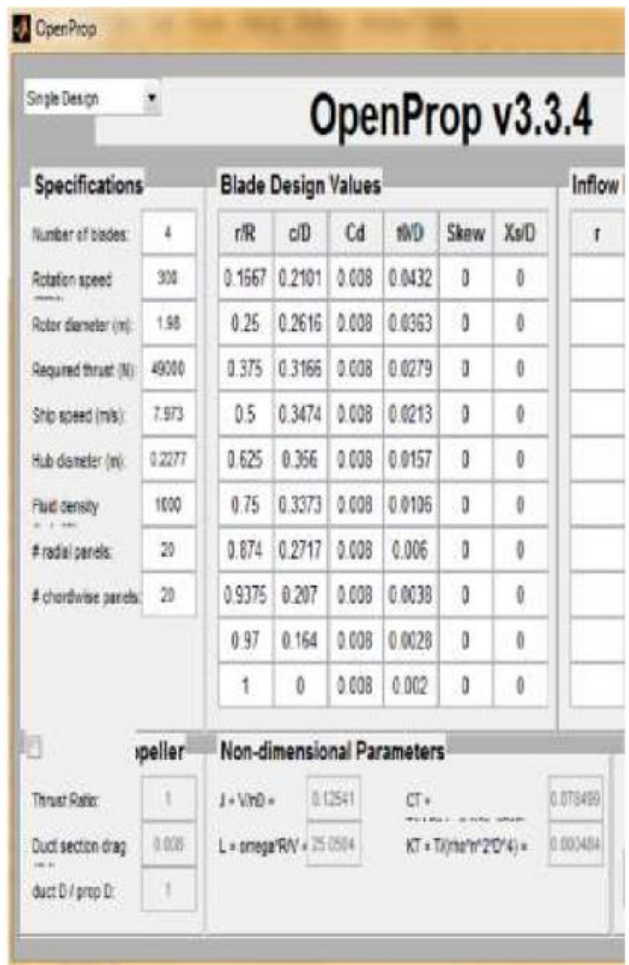

Fig. 2. MATLAB 14 application.

On importing the co-ordinate file in solid work 2013 the air foil is shown in fig (3)

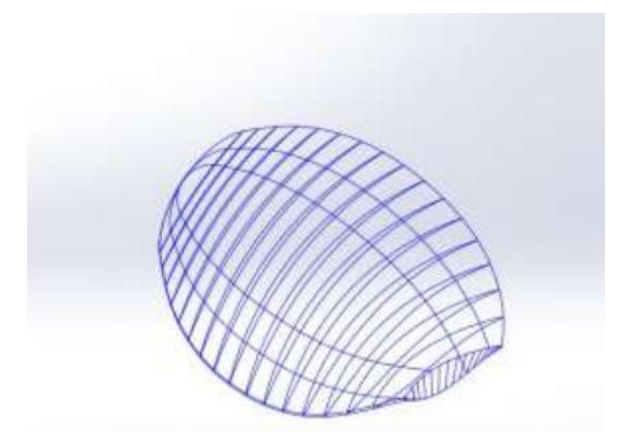

Fig. 3. Co-ordinate file imported in soild work 2013

design parameter is change to get proper arrangement for hub and blade assembly. Fig (4) show model of hub and blade respectively.

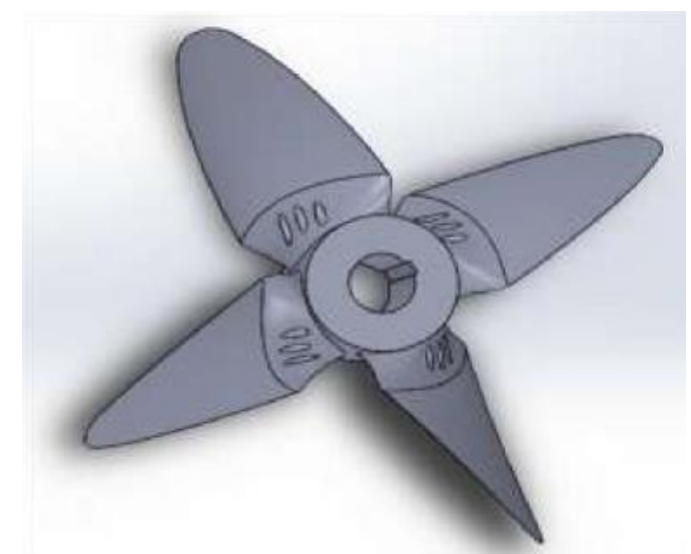

Fig. 4. CAD of model.

\subsection{Phase three}

Total assembly of propeller with bold arrangement is shown below fig. (5) in 2D and 3D view. 


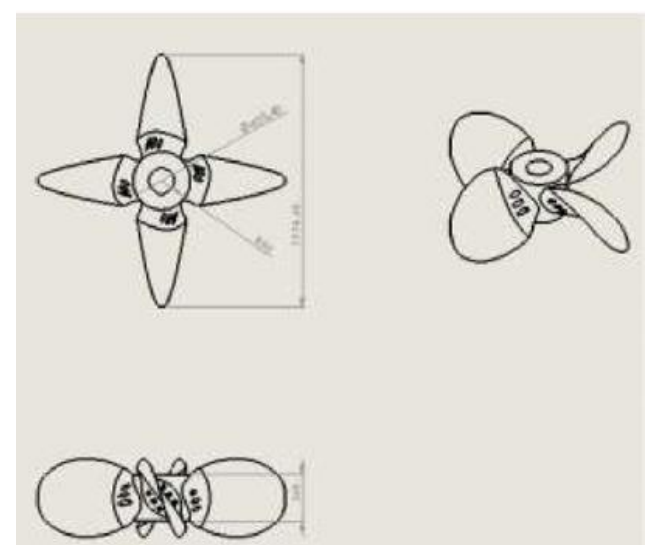

Fig.5 2D and 3D view of model.

\section{Meshing}

The solid model of the propeller blade along with hub is imported to ANSYS 14.5 and solid mesh is generated for the model. The model with mesh is shown in figure (6). Boundary conditions are applied to meshed model. The contact surface between hub and shaft is bonded.

\subsection{Mesh statistics}

Table 4. Mesh statistics.

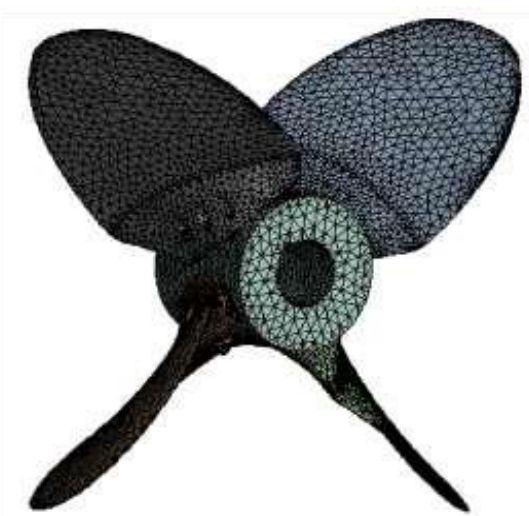

Fig.6. Mesh model in ANSYS 14.5

\begin{tabular}{|l|l|}
\hline Type mesh method & Tetrahedral \\
\hline Element size & $20 \mathrm{~mm}$ \\
\hline No. of nodes & 125334 \\
\hline No of elements & 68205 \\
\hline
\end{tabular}

\section{STATIC STRUCTURAL ANALYSIS OF MODEL}

The set of speed (RPM) and pressure (KPa) are applied on face side of the blade in the region between $0.7 \mathrm{R}$ and $0.75 \mathrm{R}$.

The thrust is produced because of the pressure difference between the face and back sides of propeller blades. This pressure difference also causes rolling movement of the underwater vehicle. This rolling movement is nullified by the forward propeller which rotates in other direction. The propeller blade is considered as cantilever beam i.e. fixed at one end and free at other end.

The Von-mises stress on the basis of shear distortion energy theory also calculated in the present analysis.

The following combination of sets are used to found stress and deformation.

Table 4. Combination set table

\begin{tabular}{|l|l|l|}
\hline Sr. no. & $\begin{array}{l}\text { Speed } \\
(\mathbf{R P M})\end{array}$ & $\begin{array}{l}\text { Pressure } \\
(\mathbf{K P a})\end{array}$ \\
\hline 1 & 200 & 2.3 \\
\hline 2 & 300 & 2.8 \\
\hline 3 & 400 & 3.3 \\
\hline
\end{tabular}


Fig (7) shows Equivalent (von-mises) stress and total deformation of the model for one of the combinations of speed and pressure $(\mathrm{RPM}=400$ and pressure $=2.8 \mathrm{KPa})$

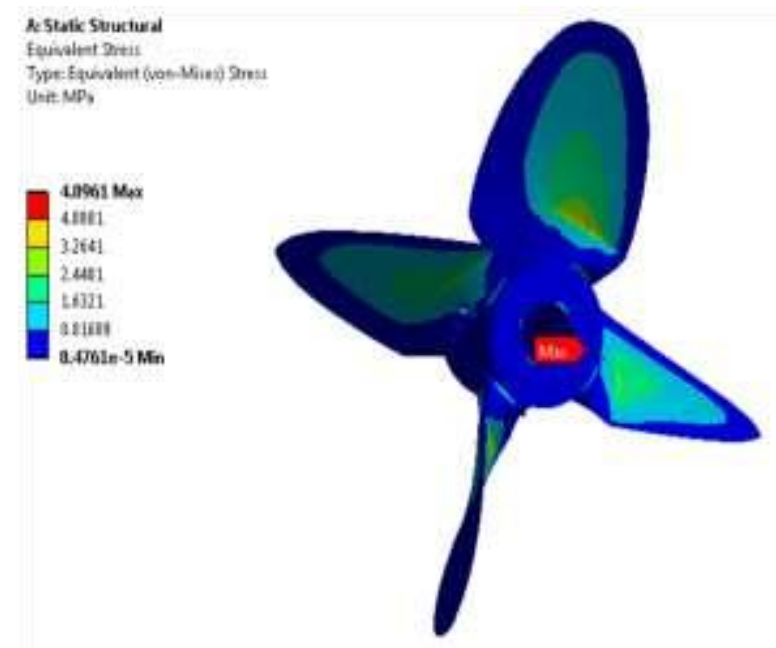

Fig.7. Equivalent stress in ANSYS 14.5

In fig (7) show that maximum stress induces at approx. $0.375 \mathrm{r} / \mathrm{R}$ is $4.8961 \mathrm{MPa}$.
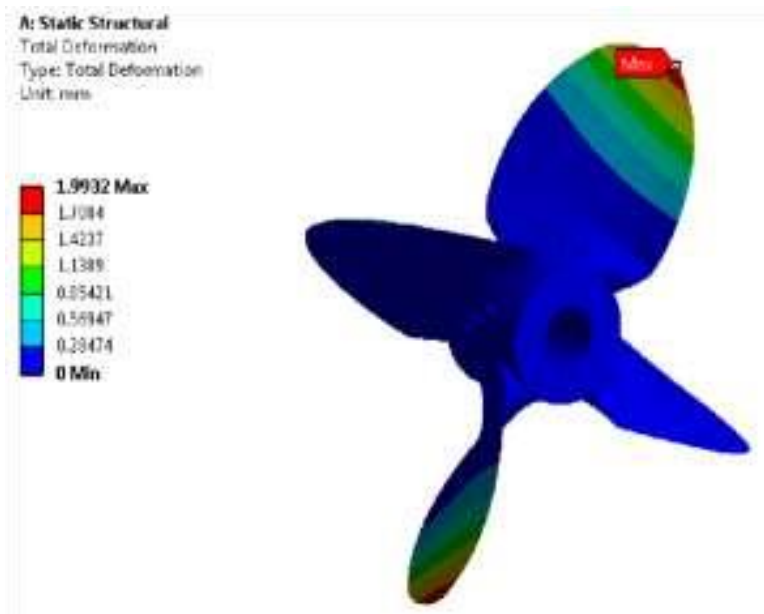

Fig.8. Total deformation in ANSYS 14.5

In fig (8) show that total deformation induce at tip of blade is $1.9932 \mathrm{~mm}$.

Like above, total 9 iteration were proceeded in same way.

Table 5. List of stress and deformation of combination

\begin{tabular}{|c|c|c|c|c|}
\hline $\begin{array}{c}\text { Sr. } \\
\text { no. }\end{array}$ & $\begin{array}{c}\text { Speed } \\
\text { (RPM) }\end{array}$ & $\begin{array}{c}\text { Pressure } \\
\text { (KPa) }\end{array}$ & $\begin{array}{c}\text { Equivalent } \\
\text { Stress } \\
\text { (MPa) }\end{array}$ & $\begin{array}{c}\text { Total } \\
\text { Deformation } \\
(\mathbf{m m})\end{array}$ \\
\hline 1 & 200 & 2.3 & 2.1657 & 1.2077 \\
\hline 2 & 200 & 2.8 & 2.4564 & 1.4304 \\
\hline 3 & 200 & 3.3 & 2.7472 & 1.6539 \\
\hline 4 & 300 & 2.3 & 3.1041 & 1.4385 \\
\hline 5 & 300 & 2.8 & 3.3445 & 1.6551 \\
\hline 6 & 300 & 3.3 & 3.6348 & 1.8733 \\
\hline 7 & 400 & 2.3 & 4.6586 & 1.7847 \\
\hline 8 & 400 & 2.8 & 4.8961 & 1.9932 \\
\hline 9 & 400 & 3.3 & 3.5901 & 0.87703 \\
\hline
\end{tabular}




\section{OPTIMIZATION RESULT BY TAGUCHI}

From above it is seen that large number of Equivalent stresses are developed in the model for 9 different combinations. As Equivalent stresses increases the fatigue life of model, we will go with "Smaller the Better" Taguchi method

Taguchi method stresses the importance of studying the response variation using the signal to noise (S/N) ratio, resulting in minimization of quality characteristic variation due to uncontrollable parameter. The Equivalent Stresses was considered as the quality characteristic with the concept of "the Smaller-the-better". The S/N ratio for the smallerthebetter is:

$$
s / n=-10 \log _{10}\left(\frac{1}{n} \sum y^{2}\right)
$$

Where $\mathrm{n}$ is the number of measurements in a trial/row and $y_{i}$ is the measured value in a run/row. The $\mathrm{S} / \mathrm{N}$ ratio values are calculated by taking into consideration above equation with the help of software Minitab 17. Taguchi approach was used for this design. The experiments were done with varying Pressure and Speed.

\section{TAGUCHI ANALYSIS}

Table 5. Response Table for Signal to Noise Ratios: Smaller is better

\begin{tabular}{|c|c|c|}
\hline Level & $\begin{array}{c}\text { Speed } \\
\text { (RPM) }\end{array}$ & $\begin{array}{c}\text { Pressure } \\
(\text { KPa })\end{array}$ \\
\hline 1 & -6.017 & -7.835 \\
\hline 2 & -8.441 & -8.648 \\
\hline 3 & -10.250 & -8.226 \\
\hline Delta & 4.232 & 0.814 \\
\hline Rank & 1 & 2 \\
\hline
\end{tabular}

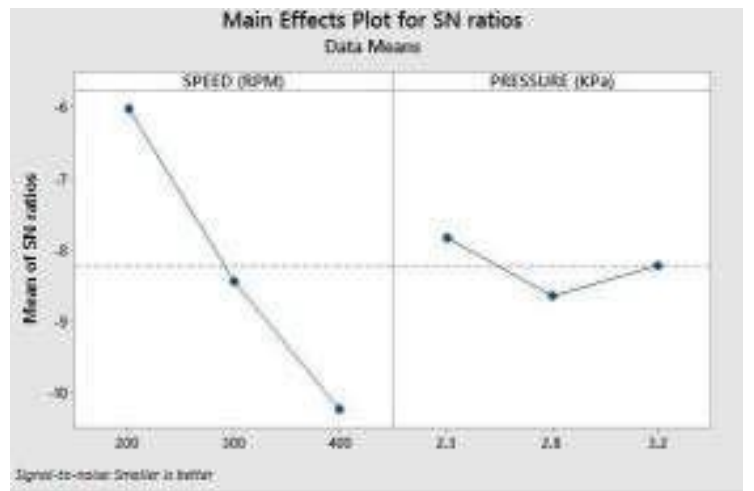

Fig.9. SN ratio plot

From taguchi analysis it is found the optimal solution from 9 combination, pressure of $2.8 \mathrm{KPa}$ and speed of $400 \mathrm{RPM}$.

\section{OBSERVATION FOR STATIC ANALYSIS}

Regardless of the category of the performance characteristics, a greater $\mathrm{S} / \mathrm{N}$ value corresponds to a better performance. Therefore, the optimal level of the machining parameters is the level with the greatest value.

Pressure: The effect of parameters pressure on the equivalent stress values is shown above fig. (9) $\mathrm{S} / \mathrm{N}$ ratio. Its effect is increasing with increase in pressure. So, the optimum level is 2 i.e., $2.8 \mathrm{KPa}$

The effect of parameters pressure on the deformation values is shown above fig. (9) $\mathrm{S} / \mathrm{N}$ ratio. Its effect is increasing with increase in pressure. So, the optimum level is 2 i.e., $2.8 \mathrm{KPa}$

Speed: The effect of parameters speed on the equivalent stress values is shown above fig. (9) for $\mathrm{S} / \mathrm{N}$ ratio. Its effect is increasing with increase in shaft speed up to 400 RPM so the optimum speed is level 3 i.e., $400 \mathrm{rpm}$

The effect of parameters speed on the deformation values is shown above fig. (9) for $\mathrm{S} / \mathrm{N}$ ratio. Its effect is increasing with increase in shaft speed up to $400 \mathrm{RPM}$ so the optimum speed is level 3 i.e., $400 \mathrm{rpm}$

\section{ROTORDYNAMIC ANALYSIS}

Rotor dynamics is a specialized branch of applied mechanics concerned with the behaviour and diagnosis of rotating structures. As the speed of rotation increases the amplitude of vibration often passes through a maximum that is called a critical speed. This amplitude is commonly excited by unbalance of the rotating structure. If the amplitude of vibration at these critical speeds is excessive then catastrophic failure occurs. The critical speed of a rotating machine occurs when the rotational speed matches its natural frequency. The lowest speed at which the natural frequency is first encountered is called the first critical speed. 
Fig. (10) show the condition applied on the model.

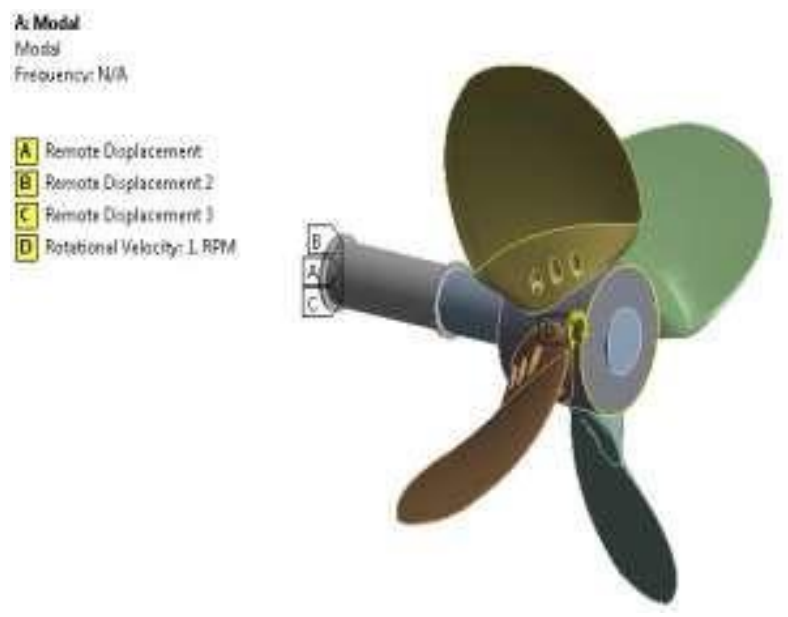

Fig.10. Condition applied on model

\subsection{Campbell diagram}

The Campbell diagram, also known as "Whirl Speed Map" or a "Frequency Interference Diagram". The natural frequencies of rotating component changes with the rotational velocity due to gyroscopic effect.

From Campbell dia., as shown above, if the excitation line and forward frequency line intersect then critical speed occurs.

\section{OBSERVATION FOR ROTORDYNAMIC ANALYSIS}

Form the above rotordynamic analysis it is found that no critical speed occur for optimum solution i.e. speed of $400 \mathrm{rpm}$ so, it is safe and system is in stable condition. From the observation it can be found that blade can be used for much more high speed.

\section{CONCLUSION}

The simulation and analysis for propeller using ANSYS 14.5 is most prominent. Statics structural and Modal analysis are performed using ANSYS. From static structural results, it is found that total maximum deformation occurs at tip of blades of propeller. Also, the maximum induced equivalent (vonmises) stress produced at $0.375 \mathrm{r} / \mathrm{R}$ i.e above root of blade approximately

Taguchi method can be most effective in optimization process. It does not optimize only parameter but also indicate the values of response through which optimum process parameter selection can be justified. The results which obtained from Taguchi are based on range of values. The values of speed (RPM) and pressure (KPa) are preselected range.

From the experimental results, as the speed of shaft increases, equivalent stresses on the blade increases and also the deformation increases. Similarly pressure increases, equivalent stresses and deformation increases. From Taguchi approach, the optimum combination of pressure and speed is found out to be of having speed 400(rpm) and pressure 2.8 $(\mathrm{KPa})$ respectively.

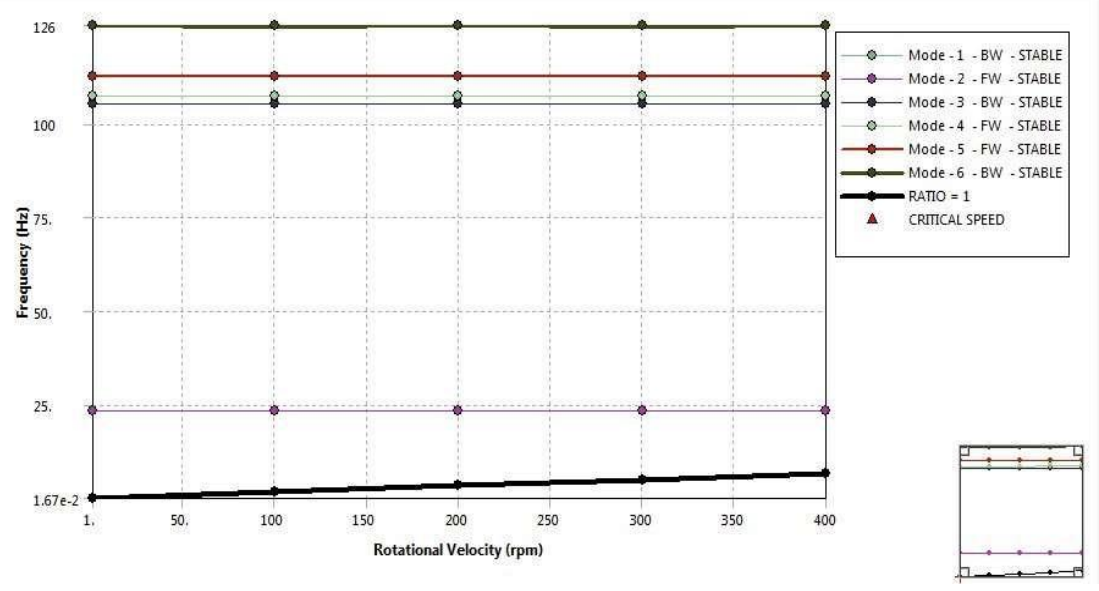

Fig.11. Campbell diagram

By performing rotor dynamic analysis, optimal speed i.e. $400 \mathrm{rpm}$ does not gives any critical speed. As there is no any critical speed occurred so it can be optimal and stable condition for speed of shaft. From the observation it can be found that blade can be used for much 


\section{REFERENCES}

[1].John. S. Carlton: Marine propeller \& propulsion second edition, p.p 01-485

[2].Analysis, Fabrication, and Testing of a Composite Bladed Propeller For a Naval Academy Yard Patrol (YP) Craft By Midshipman 1/c Christopher D. Wozniak, Class of 2005United States Naval Academy Annapolis, MD: (U.S.N.A. -- Trident Scholar Report; no. 341 (2005) ).

[3].Ejabefio, K.A (2010), Design Analysis of a Propeller for a Container Ship, Final Year Project, Department of Marine Engineering, Rivers State University of Science and Technology, Port Harcourt Nigeria.

[4].M S. Phadke 'Quality engineering using robust design', Pearson Education India Limited, Edition 2006.

[5].Carica P.M, Castrol A.M and Stern F (2010), Self-Propulsion Computations Using a Speed Controller and a Discretized Propeller With Dynamic Overset Grids, Journal Of Marine Science and Technology, 15(4), $316-330$

[6].Serkan Ekinci, (2011), A Practical Approach For Design of Marine Propellers with Systematic PropellerSeries, Znanost, Science, Brodogradnja - Shipbuilding 2 Lipanj, June 2011, Članak, Paper 714

[7].Alif, Nidal, Leif A. Carlsson, and John W. Gillespie, Jr. "Mode I, Mode II, and Mixed Mode Interlaminar Fracture of Woven Fabric Carbon/Epoxy.” In Composite Materials: Testing\& Design, Vol. 13, ed. S.J. Hooper, 82-106. West Conshohocken: ASTM, 1997. 